\title{
LITERATURA Y CINE: IMAGEN Y LETRA A LA CAZA DE NUEVOS LECTORES
}

\section{RESUMEN}

El proyecto que presentamos es un intento de compaginar el cine y la literatura para irradiar el saber literario y potenciar la competencia escritural en estudiantes de pregrado de la Universidad Minuto de Dios. Hasta el momento de aplicarlo los estudiantes no habían tenido un contacto académico con la literatura, y con el cine, sólo con las producciones comerciales. De tal suerte que iniciamos un camino abierto a nuevas experiencias. Se programaron 12 películas realizadas con base en obras "clásicas" a través de un barrido histórico, por períodos culturales hasta llegar a la época actual. Los estudiantes debían leer los textos antes de ver el film con el fin de enfatizar en algunos aspectos técnicos y/o semánticos previamente seleccionados por el docente o propuestos por ellos durante la lectura para discutirlos en grupo. Luego se presentaron informes escritos respecto a temática tratada en las discusiones grupales. De esta manera se trabajó la argumentación escrita y oral, el lenguaje iconográfico, el análisis textual literario (Barthes) y el análisis fílmico (Wolff).

Palabras Claves: cine, literatura, educación

\section{LITERATURE AND FILM: IMAGE AND TEXT IN THE SEARCH FOR NEW READERS}

\section{ABSTRACT}

The present project is an attempt to combine film and literature to promote literary knowledge and enhance writing competence in undergraduate students at the Minuto de Dios University. Until its application, students were not academically familiarized with literature and film, and consequently, a series of new experiences was set for them. The projection of twelve films based on classical works, covering different historical and cultural periods up to the present time, was carried out. Students were asked to read the text before watching each film, in order to emphasize on some technical and/or semantic aspects previously selected by the teacher or by them as objects of discussion. Then, students were asked to submit written reports of each activity regarding the topic discussed in the group meetings. In this way, students worked on their written and oral argumentation, use of iconographic language, and elaboration of literary textual analysis (Barthes) and film analysis (Wolff) .

Keywords: film, literature, education

\section{[ JUAN CARLOS RESTREPO ]}

Licenciado Español y Literatura U. de Antioquía. Magíster (c) en Literatura Colombiana. Docente Comunicación Social y Periodismo, UNIMINUTO seccional Bello. eliconia24国yahoo.com..

Recibido: 8 de abril de 2013

Aceptado: 8 de junio de 2013

\section{¿POR QUÉ?}

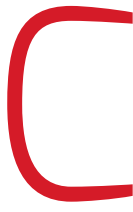

uando aquella mágica tarde del 28 de diciembre de 1895, -en el café parisino de El gran salón indio-, se mostró, ante un auditorio de anonadados espectadores una pequeña proyección de un tren que arribaba a una estación y que llevaba un grupo de obreros de una fábrica de Lyon, los hermanos Lumiere jamás imaginaron que su extraño artefacto kinetoscópico habría de evolucionar y de gestar un entorno tan complejo hasta llegar al cine que hoy conocemos.

De hecho su inicio fue más una aventura científica y mecánica que estética. Las primeras experiencias "cinematográficas” fueron en esencia de carácter documental, y se tuvo que esperar hasta que D. W. Griffith iniciara el lenguaje fílmico como tal, y que el pionero director ruso Eisenstein descubriera las grandes posibilidades que el montaje le otorgaba al conjunto, que el cine mirara con interés a la literatura para configurar el verdadero concepto de visión narrativa del llamado séptimo arte. Sin duda ha sido vertiginoso el desarrollo de la industria cinematográfica pese a su joven historia, y se podría afirmar que su tiempo de existencia es inversamente proporcional con el increíble impacto que sobre la cultura moderna ha tenido este fenómeno híbrido que se debate entre la tecnología, la industria y la estética.

Pero no es de la historia del cine de lo que pretendemos disertar en este análisis, sino de su relación directa con la literatura y de las posibilidades didácticas que esta simbiosis perfecta tiene en el campo de la enseñanza de la literatura, su difusión y permanencia en los procesos académicos tanto en los grados inferiores como, en nuestro caso, en los proyectos curriculares universitarios. Sin duda estamos 
en la época de la imagen, nuestros jóvenes utilizan cada vez más los medios audiovisuales para su comunicación cotidiana (redes sociales) como académica (clases virtuales), por lo tanto se hace indispensable integrar la imagen a los procesos de enseñanza-aprendizaje; y una manera de hacerlo con éxito es mediante la simbiosis de la literatura y el cine. En el proyecto que ilustraremos a continuación se verá cómo estas manifestaciones estéticas se complementan para ofrecer un corpus didáctico rico en posibilidades tanto cognitivas como cognoscitivas.

En un espectro que excede los estudios que abordan los problemas específicos de la adaptación literaria al cine o a la televisión, la literatura, entendida como la depositaria de la tradición narrativa de Occidente, ha sembrado la ficción audiovisual con innumerables huellas de argumentos universales que la puesta en escena ha combinado y transformado. Esta huella no sólo es reconocible en las producciones que recrean específicamente mitos o narraciones tradicionales sino también en muchas otras que se destacan por su originalidad o por ser formatos aparentemente no narrativos. Acercarse a la narrativa de los medios audiovisuales es entender que la historia habla por nosotros y que a veces el gran éxito de una película se debe a una idónea actualización de un argumento que ya fue escrito tiempo atrás, con otros personajes y en otro ambiente pero que simbolizó con gran acierto una experiencia humana individual para formar parte, incluso, del inconsciente colectivo occidental.

Nuestros estudiantes pertenecen al siglo XXI y éste es el siglo de la imagen, algunos investigadores de las Ciencias de la Comunicación como Sonia Raquel Vicente (2008) llegan a afirmar que estamos ante un evidente cambio de paradigma y que "Nos encontramos frente a un cambio cultural y a un re-posicionamiento del valor de la palabra y de la imagen como transmisoras de conocimiento e información” (Vicente, 2008, pág. 68) En este panorama pocas veces se hace tan relevante un proyecto sobre cine y literatura como vehículo de análisis y acercamiento a la literatura y al mundo cultural. Un estudiante de pregrado en el área de humanidades que no utilice esta herramienta, sin duda alguna no puede desempeñar de forma idónea su función en los procesos comunicativos. La obra literaria llevada al cine, al mostrar una época, se convierte en un fresco maravilloso en el cual se puede entender no sólo el quehacer del hombre como sujeto social, sino el desarrollo del pensamiento y, por ende, de la cultura humana. Un análisis riguroso de algunos documentos fílmicos con base en obras literarias, permite reconocer una serie de transformaciones estructurales y conceptuales que a su vez ayudan a desarrollar las diferentes competencias y subcompetencias asociadas a la macrocompetencia comunicativa tal como lo sugieren los Lineamientos Curriculares y los Estándares de Calidad para la Educación. Fuera de ello permite "atrapar y seducir” a nuevos lectores, al mostrar que la aventura del lector está llena de buenos momentos, de viajes hacia otros mundos posibles o al interior de nuestra propia realidad vista a través de la mirada de escritores y directores de cine que nos dejaron su legado para el disfrute y el conocimiento.

Edgar Dale (1955) defiende la enseñanza con películas porque:

- Obliga a la atención,

- intensifica la realidad,

- permite traer al aula el pasado y el presente,

- amplifica o reduce el tamaño de los objetos,

- sirve para presentar sucesos que no pueden ser vistos por el ojo humano,

- mejora la comprensión de conceptos y relaciones,

- puede influir en el desarrollo de actitudes, y

- ofrece satisfactorias experiencias estéticas.

\section{¿DÓNDE?}

La Corporación Universitaria Minuto de Dios Seccional Bello está situada en los límites de dicho municipio con el área metropolitana de Medellín en el extremo Nororiental, uno de los más conflictivos y deprimidos del Valle de Aburrá. Es una universidad nueva en el departamento, lleva sólo diez años prestando servicios educativos, y aunque es privada su estudiantado proviene en un alto porcentaje de los barrios aledaños (Zamora, Popular uno y dos, Machado, entre otros), circunstancia que explica, en parte, muchas de las falencias que los usuarios muestran frente a su bagaje cultural. El programa de Comunicación Social y Periodismo perteneciente a la Facultad de Ciencias Sociales, es aún más reciente que la misma universidad, la primera corte se graduó apenas el año pasado. De manera que el equipo de docentes tiene que hacer un esfuerzo muy grande para intentar llenar los vacíos académicos con que llegan los jóvenes.

Para atender las necesidades más apremiantes de la Facultad en el tema de la formación integral en el cual el componente estético es fundamental, se propuso el seminario de Literatura y Cine, como una forma de acercar a los estudiantes a la cultura literaria, en especial a las obras clásicas, además, se pensó el trabajo con la imagen para desarrollar la lectura iconográfica y los procesos narrativos de los que se sirve el cine en su propia gramática, y aquellos 
que toma prestados de la narratología y en general, de los aspectos técnicos literarios.

\section{¿DESDE QUÉ PERSPECTIVA?}

Desde el punto de vista fílmico partimos de los argumentos del director y crítico argentino Jorge Wolff (2001) quien plantea que el cine y la literatura son dos artes con formatos y gramáticas diferentes pero que se prestan elementos para configurar un todo narrativo, es así como también el análisis de una película basada en un texto literario debe conservar su propia independencia de un análisis literario propiamente dicho, es por ello que se suele tener como punto de partida la comparación entre las dos manifestaciones: la novela y la película, al quedar en deuda una u otra, bien porque se omitió algo en la trama, por ejemplo, o bien porque la versión cinematográfica supera en muchos aspectos a la novela, como sucedió con "Lo que el viento se llevó".

Desde el punto vista lingüístico, partimos de la concepción de Umberto Eco, expuesta en sus libros Obra abierta (1962) según la cual en el acto de lectura ocurre una interacción entre los saberes del texto y los saberes previos del lector, a estos últimos se les denomina enciclopedia cultural del lector.

Desde el punto de vista de las teorías de la lectura, optamos por abordar la propuesta de Margarita de Sánchez y Donna Marie Kabalien, expuesta en su texto La lectura analítico - crítica (1988). En ella -se planteacomo proceso fundamental de interacción con el texto, la lectura analógica, que alude a las múltiples relaciones de funcionalización de la información del texto hacia los contextos que lo rodean.

Desde el punto de vista de la teoría literaria, concebimos el análisis del relato desde una perspectiva estructural, tal como la expone Roland Barthes en su Análisis estructural del relato (1979). Conceptos como narrador, punto de vista, tiempo o secuencialidad se convierten en los principales elementos a desarrollar en el análisis de texto.

Desde el punto de vista del impacto de la lectura en la cultura y de la lectura literaria en la reformulación del aprendizaje, partimos de las reflexiones -no pretenden ser propiamente teoría- de George Steiner (Lenguaje y silencio, Extraterritorial), y Harold Bloom (2001) (El canon occidental), quienes plantean que a la literatura le cabe representar cualquier vivencia social y psicológica.

Se proponen referentes teóricos desde estos cinco ángulos, ya que a la hora de hacer una reconstrucción de las prácticas pedagógicas y proponer a partir de los hallazgos conceptuales un mejoramiento del ejercicio docente, es absolutamente necesario delimitar las concepciones sobre los distintos procesos y aspectos involucrados en algo tan complejo como enseñar literatura a través del cine.

Encontramos, en este sentido, varios ejes, alrededor de los cuales discurrió la propuesta:

¿Qué es leer?

¿Qué es interpretar el contexto?

¿Qué es el análisis narrativo?

¿Qué es interdisciplinariedad?

¿Qué es leer imágenes?

Para el primer eje, intentamos emplear una teoría que describiera de la mejor manera posible la interacción que el lector tiene con los saberes del texto. En Umberto Eco, hallamos una respuesta a tal fenómeno en la descripción que hace en sus libros Obra abierta y Lector in fábula, en los cuales desarrolla el concepto de enciclopedia cultural. En el caso de la aproximación a relatos que poseen claros referentes científicos, la enciclopedia cultural que demandaría su lectura es propiamente científica. Sin embargo, aunque la descripción de los mecanismos que intervienen en esta confrontación de saberes en la lectura es válida psicológicamente, dista de ofrecer una descripción satisfactoria de los procesos lingüísticos y cognitivos que intervienen en esta interacción.

Por tal razón, se recurrió a una teoría sobre la lectura de sesgo más cognitivo y con una mayor aplicabilidad. Tal teoría es la que presenta el texto Lectura analítico crítica (1998) de Donna Marie Kabalien y Margarita de Sánchez, en el que se plantea que cuando alguien lee algo debe remitirse a los diferentes contextos en que está inscrita la información, al dar lugar a un proceso denominado funcionalización, que consiste en la aplicación de principios analógicos al contraste de información presente en el texto y la información presente en los contextos (biográfico, social, cultural, histórico).

Ahora bien, este proceso de funcionalización es válido para cualquier tipo de texto, aunque hay una mayor aplicabilidad de estos principios de análisis textual a la lectura de textos informativos y argumentativos. Como en el caso de este proyecto se trataba de emplear relatos en lugar de ensayos o artículos de divulgación, se debía recurrir a un modelo de análisis textual que diera cuenta de algunos aspectos técnicos del género narrativo, al favorecer el análisis de problemáticas científicas. Fue así como se decidió en recurrir a las categorías de análisis estructuralista pro- 
puestas por Roland Barthes en su Análisis estructural del relato(1970): tiempo, espacio, personaje, secuencia...

El proyecto "Literatura y cine" hace énfasis en la competencia comunicativa que el cine proporciona al futuro egresado, mediante el acercamiento a grandes producciones que el Séptimo arte ha realizado al tomar sus guiones de clásicos literarios reconocidos por la crítica como pertenecientes al canon por su alto valor estético y su permanencia como paradigmas de escritura a lo largo del tiempo. Entendemos como competencia comunicativa un cúmulo de subcompetencias asociadas mediante la unión de las competencias pragmática y textual, estas subcompetencias son la estética, la enciclopédica, la poética, la semántica, la quinésica y la sintáctica, según los profesores Girón y Vallejo (1992): "La competencia comunicativa comprende las aptitudes y los conocimientos que un individuo debe tener para poder utilizar sistemas lingüísticos y translingüísticos que están a su disposición para comunicarse como miembro de una comunidad sociocultural dada” (Girón y Vallejo, 1992, pág. 45)

De tal forma asumimos la imagen como un texto en el cual hay un acto comunicativo que debe ser decodificado, en este caso por el espectador.

¿CÓMO?

Para indagar sobre los saberes literarios previos de los estudiantes se aplicó un instrumento sencillo (ver apéndice 1), en el cual se debían relacionar 50 autores clásicos, o a la manera de Harold Bloom, del Canon de Occidente (2001) "supuestamente" conocidos por cualquier estudiante de este país, ya que están sugeridos en el componente de literatura de los Estándares para la Calidad de la Educación, con sus obras más relevantes. Los resultados fueron los que suponíamos, es decir de muy bajo nivel: de los 30 estudiantes sólo 2 reconocieron 5 autores con sus obras (vale decir que habían algunos textos que ya pertenecen a la cultura como El Quijote, Romeo y Julieta, sólo para citar algunos) y los 28 restantes acertaron entre 1 y 4 escritores.

Aunque este diagnóstico prueba únicamente la competencia enciclopédica, es preocupante el grado de desconocimiento que poseen los estudiantes y más teniendo en cuenta que el programa es básicamente humanístico y que el proyecto se aplicó a estudiantes de $6^{\circ}$ semestre. Como veremos más adelante, al final de las sesiones ese déficit quedó en parte cubierto mediante un trabajo que se caracterizó por el aprendizaje significativo y la fijación del conocimiento (metacognición) por doble vía: imagen y palabra.
Para ello se construyó un recorrido paralelo desde los inicios del cine con los hermanos Lumiere en Francia, al pasar por Griffin quien le dio estatus narrativo al concepto de film documental, luego se estudiaron los movimientos más importantes como el expresionismo, el nuevo cine francés, el fenómeno Hollywood y sus grandes producciones, el cine latinoamericano hasta llegar al colombiano. Al mismo tiempo se intentó dar una secuencia cronológica y taxonómica a través de escoger progresivamente obras de la historia de la literatura desde el clasicismo grecorromano (v.g "El satiricón” de Petronio, llevada al pantalla por F. Fellini) hasta culminar con la novelística latinoamericana del siglo XX y XXI llevada al cine como "Doña Flor y sus dos maridos" de G. Amado y La mansión de la Araucaíma, relato de Mutis y convertido en guión cinematográfico por Carlos Mayolo. Es de anotar que se leyeron, si no todos, algunos de los textos literarios (esto por asuntos de tiempo) y documentos de apoyo crítico en los ámbitos de la estética del cine y de la literatura. A los estudiantes se les dio la bibliografía que sería la base de la película y se indicó el contenido a leer, es decir si se debería abordar la lectura de todo el texto (como en el caso

\section{Entendemos como competencia comunicativa un cúmulo de subcompetencias asociadas mediante la unión de las competencias pragmática y textual, estas subcompetencias son la estética, la enciclopédica, la poética, la semántica, la quinésica y la sintáctica}

de El proceso de Kafka) o uno o varios capítulos (como en el caso de Ana Karenina de Tolstoi) o sólo fragmentos (como en Lolita de Nabokov). Planeamos cada sesión de 3 horas con el fin de poder ver, leer y hablar sobre el documento fílmico y el escrito, deteniéndonos en aquellos aspectos que merecían un análisis detallado y al volver a los planos que requerían una "relectura".

Las herramientas metodológicas fueron las siguientes:

Clase magistral en los temas conceptuales sobre elementos técnicos de cine, teoría, análisis literario y fílmico, historia literaria y contexto social.

Estudio individual de documentos teóricos sobre cine y literatura (ver bibliografía)

Análisis y discusión grupal de textos fílmicos y literarios, socialización de trabajos individuales.

Escritura individual de informes argumentativos

Presentación grupal de películas, observación individual de películas 
Cine-foro

Investigación grupal de un autor y un director para cine foro final a la comunidad universitaria

Se sugirió la siguiente ruta para los encuentros.

Historia del cine primera parte. El mundo grecolatino a través de Federico Fellini: El satiricón de Petronio

Historia del cine segunda parte. El cine en el aula. La visión medieval a través de Pasolini: El Decamerón de G. Bocaccio y Los cuentos de Cantherbury de G. Chaucer

Algunos aspectos técnicos: el montaje y el rodaje, el plano y la secuencia. La Europa Ilustrada a través del Marqués de Sade en Justine

El realismo: dos mujeres en el cine: Madame Bovary y Anna Karenina

La entrada en el caos interior: El Proceso (Orson Wells) y Muerte en Venecia (Luccino Visconti), escritas por Kafka y T. Mann respectivamente.

Otros mundos: el cine de ciencia ficción: de Mary Shilley a Philip K. Dick con Frankeinstein y Sueñan los androides con ovejas eléctricas (llevada al cine como Blade Runner).

Lolita de Nabokov o la mirada interior de la depravación inocente

Literatura y cine latinoamericano (El beso de la mujer araña de Manuel Puig, película de Héctor Bibanco, y Doña Flor y sus dos maridos de Jorge Amado, cine por Barreto).

Literatura y cine colombiano: La mansión de la Araucaíma de Mutis por Mayolo y El coronel no tiene quien le escriba de García Márquez por Rubinstein

El cine como fenómeno social. El concepto de cineforo (el cine club)

\section{RESULTADOS}

Se logró conformar el Cine Club "Empeliculados" (con énfasis literario) con quienes hicieron parte del proyecto, abalado por las directivas de la universidad.

Se realizó un ciclo de "Literatura y Cine" en la semana de las comunicaciones universitarias en la que de martes a viernes se presentaron cuatro proyecciones escogidas por los estudiantes La colmena de Camilo José Celá; Crónica de una muerte anunciada, de García Márquez; El resplandor de Kubrich, y Lolita de V. Nabokov; y presentadas por ellos con la metodología del cine foro.
Se incluyó el proyecto como curso fijo del plan de estudios del programa de Comunicación Social y Periodismo

Se creó un equipo interdisciplinar para programar eventos relacionados con la literatura y el cine

Se creó una expectativa favorable para esta actividad en los estudiantes de semestres inferiores quienes desde ahora desean participar del mismo

Se constituyó el semillero de Literatura y Cine UCRÓNICO

El semillero presentó a la Biblioteca España un proyecto de cine clubes escolares y apreciación cinematográfica para jóvenes de la Comuna Uno con alta vulnerabilidad llamado "Cinexcusa" el cual se está llevando a cabo.

\section{¿QUUIÉNES?}

El proyecto fue ideado y llevado a cabo por el docente de la Corporación Universitaria Minuto de Dios Juan Carlos Restrepo Botero, licenciado en Lengua Castellana de la U. de A., con la asesoría y apoyo directo del comunicador de la U. de A. Robin Mejía coordinador del programa Comunicación Social y Periodismo de UNIMINUTO seccional Bello.

\section{BIBLIOGRAFÍA}

Academia. (1995, Octubre). Revista del cine español. (No. 12).

Barthes, R. (1996).El grado cero de la escritura. Madrid: Siglo XXI.

Barthes, R., Greimas y otros. (1970). Análisis estructural del relato. Communications, (No. 8). Buenos Aires: Tiempo Contemporáneo.

Benjamín, W. (1982). Discursos interrumpidos. Madrid: Taurus.

Bloom, H. (2001).El canon occidental. Barcelona: Anagrama.

Calvino, Í. Por qué leer los clásicos. Barcelona: Tusquets.

Dale, E. (1955). Redbrick and these Vital Days. Madrid: Gredos.

Eco, U. (1962).Obra abierta. Barcelona: Lumen.

(1987).Lector in fabula. Barcelona: Lumen.

Geruld, H. (1981). Los escritores frente al cine. Madrid: Fundamentos. 
Girón, M.y Vallejo, M. (1992).Producción e interpretación textual.Medellín: Editorial Universidad de Antioquia.

Peña-Ardid, C. (1992).Literatura y cine. Madrid: Ediciones Cátedra.

Sánchez, M.yKabalien, D. (1998).Lectura analítico crítica. Madrid: Siglo XXI.

Vicente, Sonia Raquel. (2008) El rol de la imagen en el mundo contemporáneo. Huellas, Búsquedas en Artes y Diseño, (No. 6). Mendoza, Argentina. 